\title{
Association of Myostatin Gene Polymorphisms with Strength and Muscle Mass in Athletes: a Systematic Review and Meta-Analysis of the MSTN rs1805086 Mutation
}

\section{Aksenov Maxim Olegovich ( $\square$ aksenov.mo@rea.ru )}

Plekhanov Russian University of Economics. Banzarov Buryat State University https://orcid.org/00000002-0079-5750

Marek Kruszewski

Jozef Pilsudski University of Physical Education in Warsaw https://orcid.org/0000-0001-9476-0016

\section{Systematic Review}

Keywords: myostatin, muscle, strength, hypertrophy, hyperplasia, training, meta-analysis

Posted Date: February 9th, 2022

DOI: https://doi.org/10.21203/rs.3.rs-1342135/v1

License: (c) (1) This work is licensed under a Creative Commons Attribution 4.0 International License. Read Full License 


\section{Abstract \\ Introduction.}

Variant (rs1805086, c.458A>G, p.Lys(K)153Arg(R), (K153R) of the myostatin gene (MSTM) has been associated with a skeletal muscle phenotype (hypertrophic response in muscles due to strength training). However, there are not enough reliable data to demonstrate whether the $\mathrm{K}$ and $\mathrm{R}$ allelic variants of MSTN rs1805086 are valid genetic factors that can affect the strength phenotype of athletes' skeletal muscles.

\section{Purpose.}

To conduct a systematic review and meta-analysis of the association of MSTN rs 1805086 polymorphism with the strength phenotype of athletes.

\section{Materials and methods.}

This study analyzed 71 research articles on myostatin and performed a meta-analysis of MSTNK153R rs1805086 polymorphism in strength-oriented athletes and control (non-athletes) group.

\section{Results.}

It was found that athletes in the strength-oriented athletes group had a higher frequency of the $\mathrm{R}$ minor allele than that in the control group $(\mathrm{OR}=2.02, \mathrm{P}=0.05)$.

\section{Conclusion.}

Thus, the obtained results convincingly demonstrate that there is an association between the studied polymorphism and strength phenotype of athletes; therefore, further studies on this association are scientifically warranted.

\section{Introduction}

\section{History of Discovery}

In addition to sports training, environmental exposure, nutrition, and the professional activity of a person, genetic factors also have a great influence on the strength indicators of an athletes' skeletal muscles [1]. The study of genetic foundations, including gene polymorphisms and their connections with a body's resistance to physical load as a whole, and their contribution to an athletes' strength abilities and 
development should reasonably be considered as one of the most important and significant areas of modern sports science [2].

Myostatin (MSTM) protein was discovered in 1997 and was encoded by MSTN gene, located on chromosome 2 2q32.2; it encodes 375 amino acids in three exons and occupies a site of approximately 8 $\mathrm{kb}$ [3]. This discovery was considered a significant success in the study of genetic factors for increasing muscle mass and developing strength abilities.

This gene was named myostatin because of its ability to inhibit muscle differentiation and growth [4], whereas the overexpression of myostatin is associated with muscle atrophy [5]. However, these studies have confirmed the central and critical role of MSTN in suppressing muscle growth [6, 7].

Special attention is given to MSTN because the very first publications on this factor concluded that its absence affects the increase in muscle mass due to hypertrophy and hyperplasia of the muscle fibers [8]. The increase in detailed scientific studies of MSTNand the possibilities of using the published data for various biomedical and sports purposes, including gene doping [9] has increased the interest in the subject.

The ability of MSTN to limit the growth of muscle mass immediately attracted the attention of researchers as it can be used in sports and sports medicine.

MSTN, also known as the growth differentiation factor-8 (GDF-8), is a protein-based hormone that acts as a negative regulator of muscle growth. This was first mentioned by McPherron et al. [10]. The authors found that a mutation in MSTN leads to an increase in the size of muscle tissue. During the initial stages, these were primarily conducted on animals followed by on humans. MSTN is particularly of interest in sports, wherein one can monitor its correlation with the performance, especially in sports that require muscle strength and mass [10].

Mutations in MSTN lead to a significant increase in muscle mass [11]. It is an important gene that affects myogenesis as its role is to regulate the growth and differentiation of muscle cells [12]. In particular, the genetic predisposition to gain muscle mass is due to the low expression of MSTN, which is advantageous in the improvement of strength [13].

As MSTNis the most common type of skeletal muscle, it is of interest in studies related to sports science [14]. However, its expression is also noted in the heart and adipose tissues $[15,16]$.

The growing interest in MSTN has led to the publication of a large number of scientific papers that can be found in the Web of Science and PubMed database (Fig. 1). A review of the publications confirms that MSTN is an endogenous negative regulator of skeletal muscle mass, which acts as an antianabolic agent that suppresses the activation, replication, DNA and protein synthesis of muscle satellite cells affecting myogenic differentiation [17]. 
Researchers from Taiwan found that MSTN was negatively correlated with age and the percentage of fat mass in healthy young men [18]. The results of the experiments proved that the reference value of MSTN concentration in blood serum in healthy young men is $12.3 \pm 3.6 \mathrm{ng} / \mathrm{mL}$ and that it negatively correlates with age [19].

Considerable attention should be paid to the factors contributing to the inhibition of MSTN expression. According to scientific sources, such factors include hypodynamia, various origin diseases, state of weightlessness, and aging $[9,20]$. The level of MSTN in skeletal muscles is also influenced by poweroriented physical exercise [21].

\section{MSTN Inhibitors}

There are a number of factors that act as inhibitors of MSTN synthesis, including myocyte 2 enhancing factor (MEF2); gamma-receptors activated by peroxisome proliferator (PPARY); MyoD; and hormones, such as insulin-like growth factor (IGF-1), angiotensin II, thyroid hormone, erythropoietin [22], sex steroids, follistatin, and estradiol [23].

One of the main factors in sports that significantly affect the level of MSTN secreted is power-oriented physical activity, hypoxia, and dietary supplements. Moreover, the production of MSTNis influenced by essential amino acids, which are often consumed by athletes after intensive training [24].

Currently, the study of antibodies against MSTN, e.g., MYO-029 and BYM338, are attracting much attention, but their effectiveness is still poorly studied $[25,26]$. In addition to antibodies, other MSTN inhibitors, such as the hormone follistatin, can also suppress its activity [27-29].

Recent studies have shown that essential amino acids suppress MSTN expression in human skeletal muscles [30, 31].

In high-performance sports, myostatin inhibition is prohibited by WADA (https://www.wadaama.org/en/prohibited-list/prohibitedat-all-times/hormone-and-metabolic-modulators).

MSTN is a potential genetic marker of the athletic abilities in strength sports because of the involvement of a large number of skeletal muscles and the functions of myokines. Some research related to the study of MSTN and its role in hypertrophy and skeletal muscle strength seemed contradictory [20,32,33]. Therefore, in this study, attention was given to the influence of the $K 153 R$ rs 1805086 genotype on the manifestation of skeletal muscle strength in athletes.

\section{Mechanism of Effect of MSTN on Skeletal Muscle Mass and Strength}

Physical activity causes muscle hypertrophy, and performing physical power-oriented exercises clearly demonstrated this. This type of exercise causes mechanical damage to sarcomeres and sarcolemmas. After a certain period of time, the balance shifts toward protein synthesis and, as a result, phenotypic changes increase the volume and strength of skeletal muscles. These processes release active MSTN, 
which affects satellite cells and fibroblasts located near the damaged area. MSTN can cause protein degradation in myofibrils, which are important for the normal functioning of muscle fibers as they removes unnecessary, wasted proteins from the muscle cells [34].

MSTN is one of the main factors associated with muscle atrophy. In studies involving humans, it was found that by the 25th day of the sedentary regime, the level of myostatin increased by $12 \%$ [9]. Myostatin can regulate the function of muscle fibers and nearby cells, which include fibroblasts and satellite cells or satellites. Mature muscle fibers are the products of final differentiation [28].

An increase in muscle size is achieved by the fusion of satellite proliferating cells with fibers. Primarily, microtrauma in a single muscle fiber act as a stimulus for the proliferation of satellite cells in adult organisms. When these cells are activated and emerge from a dormant state, genes characteristic of myoblasts are also activated. Therefore, satellite cells become myoblasts that migrate to the damaged areas of muscle tissue and depending on the degree of damage, either merge with the damaged muscle fiber (hypertrophy) or merge with each other, thus creating new fibers (hyperplasia). Therefore, satellite cells regulate the functional state of skeletal muscles in the adult body. They are necessary for the restoration of damaged muscle fibers and are a source of additional nuclei in case of muscle hypertrophy after training sessions. MSTN negatively affects the proliferation of satellite cells [35]. Power-oriented training sessions result in mechanical stretching of the muscle and lead to microdamage. There is also evidence that MSTN negatively regulates the activation of resting satellite cells, hindering their development. Such inhibitory effects are necessary for normal muscle regeneration as premature fusion of satellite cells with myofibrils can impair muscle fiber functions (Fig. 2).

In general, the mechanism by which MSTN controls the number of muscle fibers is not well studied. It is synthesized as an inactive protein and undergoes changes to turn into mature active form in two stages [36]. It enters the bloodstream as a latent precursor protein and undergoes a proteolytic process, turning into a mature peptide that binds to the extracellular type II receptor (ActRIIB) activin. Binding of MSTN to ActRIIB induces the intracellular activation of proteins, by which MSTN modulates the proliferation and differentiation of myoblasts, and ultimately, the muscle mass [30, 37, 38].

\section{Effect of Myostatin on Tendons and Bones}

Tendons are an important component in the manifestation of maximum strength of the skeletal muscle. Weightlifting and speed-strength sports athletes with high indicators of skeletal muscle strength often have tendon injuries as their muscle strength exceeds their endurance. During strength training, fibroblasts proliferate, collagen synthesis increases, and the cross-sectional area of the tendons increases to make them stiffer. This allows the tendons to withstand high-intensity physical loads and reduce the risk of damage to them [39].

MSTN can change the mechanical properties of tendons by impairing their ability to stretch, increasing the risk of damage. Such data cast doubt on the feasibility of inhibiting MSTN expression for sports purposes [35]. The exact mechanisms of the effect of myostatin on tendons and ligaments are still 
unknown, and further studies are needed to assess its regulatory role in these processes [40]. When studying the regeneration of muscles and tendon fibroblasts, it is assumed that myostatin affects the expression of type 1 collagen. Recent studies have reported that local injections of exogenous myostatin during tendon healing increase the cross-sectional area of the tendon [41].

In both human and animal studies, there is evidence that myostatin is an important regulator of muscle mass as well as bone density. The mechanisms by which myostatin regulates bone formation are not completely understood, but it is clear that it has a direct effect on the proliferation and differentiation of stem cells $[42,43]$. Since myostatin and its receptor are expressed during bone regeneration, it affects bone density [43]. It is likely that myostatin directly affects bones, increasing bone mineral density. Some features of different phenotypes may be associated with increased biomechanical load, e.g., in weightlifters or under the influence of other factors, such as mechanical growth factors or growth hormones. These issues have yet to be studied in more detail, but if a number of studies prove that myostatin does have an effect on bones, then it can be assumed that myostatin inhibitors will be useful not only for increasing muscle mass, but also for bone density. This assumption is supported by recent data showing that myostatin significantly increases bone volume during fibular healing [44].

\section{Myostatin Mutations}

In previous studies, it was found that a number of missense substitutions in exons 1 and 2 of MSTN are of great interest to researchers to confirm MSTN connection with athletes' strength abilities, muscle hypertrophy [45] and recovery after intensive strength exercises. The polymorphisms K153R, A55T, E164K $P 198 A, I 225 T$ and $c .373+5[20,46,47]$ are of particular interest to the gene as well.

\section{MSTN Mutation (rs397515373, c. $373+5$ G>A)}

This mutation is very rare, with an average prevalence of $0.0004 \%$ in the population. It was necessary to obtain 500,000 samples to detect a mutation once. In 2004, a paper describing a case of MSTN mutation in a child was published [48]. In both the allelic copies of MSTN, the newborn boy had mutations that suppressed the synthesis of the functioning myostatin protein. The child was observed to have enlarged muscles of the thighs and upper extremities at birth. Ultrasonography of this child showed that the crosssection of the quadriceps femoris muscle was 7.2 SD, which was higher than the average ( \pm standard deviation) value for 10 persons matched for age and gender. Moreover, the thickness of his subcutaneous fat was 2.88 SD below the average value of that of his peers. All reflexes of the child were normal, except for those associated with tendons. Interestingly, this mutation was also present in other members of this family. One of the relatives was extraordinarily strong, and the 24 -year-old mother of the child was a professional athlete and had developed muscles, although to a lesser extent than her son. This study showed for the first time that the MSTN rs397515373 mutation (c.373 + 5 G>A) leads to an increase in muscle mass and strength $[49,50]$.

\section{MSTN A55T Mutation (rs180565, $163 \mathrm{G}>A$ )}


$A 55 T$ is important for the stability of the inhibitory activity of myostatin and affects mature myostatin [51].

A study devoted to physical exercise reported that subjects with $A T$ and $T T$ genotypes of the $A 55 T$ polymorphism had greater muscle hypertrophy than those with $A A$ genotype after 8 weeks of exercise with weights [52]. Studies have shown that myostatin polymorphisms can affect the skeletal muscle phenotype after exercise with weights. However, previous studies of myostatin SNPs associated with muscle hypertrophy in response to prolonged power-oriented strength exercises have not confirmed pronounced muscle hypertrophy after strength physical load [53].

Studies on an Asian sample set $(n=500)$ showed that the A55T polymorphism can affect the activity of myostatin, mass of skeletal muscles, and the amount of fat in the body. The results have shown that the $A 55 T$ polymorphism determines the genetic predisposition to the development of excessive obesity and low muscle mass in Asians [54].

Chinese scientists found that people with the genotype $A T+T T$ of the A55T polymorphism of MSTN showed a significant increase in the thickness of biceps $(0.292 \pm 0.210 \mathrm{~cm}, P=0.03)$ but not quadriceps $(0.254 \pm 0.198 \mathrm{~cm}, P=0.07)$ compared to those of the carriers of the $A A$ genotype. Thus, the obtained results suggest a possible association between polymorphism $A 55 T$ and muscle hypertrophy caused by strength training in Chinese individuals [52].

Korean researchers have found that the $A 55 T$ polymorphism is associated with skeletal muscle recovery after strength training. The study sample included 48 young healthy college students (age $24.8 \pm 2.2$ years, height $176.7 \pm 5.3 \mathrm{~cm}$, weight $73.7 \pm 8.3 \mathrm{~kg}$ ) who performed 50 repetitions in strength exercises. The A55T polymorphism was classified into the homozygous allele of $\operatorname{MSTN} A 55 T(A A, \mathrm{n}=34.72 \%)$, heterozygous allele of MSTN A55T (AT, $\mathrm{n}=13.26 \%)$, and homozygous mutant carriers $(T T, \mathrm{n}=1.2 \%)$. After strength exercises, subjects with heterozygous AT showed significantly faster muscle recovery than those in the $A A$ group $(P=0.042)$. These results prove that the $A T$ genotype of the $A 55 T$ polymorphism is associated with a faster recovery of skeletal muscle strength after intense strength exercise [55].

Turkish scientists failed to identify the relationship between the A55T polymorphism and the morphological data of arm wrestlers $[52,55,56]$. Moreover, no statistically significant relationships have been found in highly qualified athletes in endurance sports $[57,58]$.

\section{Mutation of MSTN E164K rs35781413 (c.490G>A, p.Glu164Lus)}

In a number of studies related to the influence of this genotype on the phenotype of athletes and people not engaged in sports, the results of experiments showed no statistically significant differences [59]. This is also due to the very low frequency of this genotype in humans. According to the website http://www.ensembl.org, the average frequency of a rare allele was $1 \%$. Such a low allele frequency obviously limits the possibility of studying large groups of people with minor alleles [47]. 
There are only indirect assumptions that this mutation can affect the manifestation of muscle mass and strength in humans. These assumptions are based on the fact that this polymorphism can make a significant contribution to the biochemical variability of mature myostatin, and accordingly, affect the state of the vertebrate muscular system. However, this assumption requires further study [9].

\section{Mutation of MSTN K153R (rs1805086, p.Lys153Arg, c.458A>G)}

The RR genotype of the MSTN rs1805086 gene is more common in top-class athletes of weightlifting [60]. Some researchers found a positive association between the K153R rs1805086 allele and the manifestation of strength abilities and muscle hypertrophy $[13,46,52,61]$, whereas other researchers did not find any significant connection [33, 46, 62]. Some studies have proven a connection with high performance in high jumps $(P<0,05)[46]$. Studies on the relationship between $K 153 R$ and skeletal muscle phenotypes in elderly Caucasian women have shown that the heterozygote MSTN rs $1805086 \mathrm{KR}$ is a favorable genotype for the increased muscle mass in the biceps of the shoulder [63].

In studies conducted on 16 women and 34 men of the Caucasus native and African-American and AfroEuropean ethnicities that participated in the European Championships and the Olympic games in sports, such as football $(n=4)$, basketball $(n=10)$, tennis $(n=6)$, volleyball $(n=6)$, canoeing $(n=2)$, rugby $(n=$ $10)$, baseball $(n=6)$, and track-and-fields (sprint, javelin, and shot put) $(n=6)$, who were compared with a control group of 100 people, including 40 women and 60 men that not involved in sports, the authors failed to find statistically significant differences between the elite athletes and people in the control group in terms of the allele K153 occurrence frequency and the success in competitions [61].

Studies on the relationship between myostatin and muscle pathologies in healthy elderly people are contradictory [64]. The association between low myostatin levels and low skeletal muscle mass was observed only in men and not in women. The authors point to the need for further research on myostatin as a biomarker of muscle mass and strength [20].

Allele Frequency of MSTN K153R (rs1805086)

According to the Ensembl database, the frequency of the rare allele $153 \mathrm{R}$ is on an average $7 \%$ (3\% in Caucasians and $22 \%$ in Africans), and large sample sizes are necessary to reliably identify the association of this polymorphism with strength abilities and muscle hypertrophy (Figure 3 ).

The conducted studies could not always prove the connection between the athletes' skeletal muscle strength, muscle mass, and competitive performance [32, 62]. Due to the low frequency of K153R polymorphism in Caucasian athletes of cyclic sports, the authors point out the possibility of evaluating MSTNK153R polymorphism during sports selection and that this mutation needs further study.

The problem of studying mutations in MSTN is the low frequency of some alleles. To obtain the required number of subjects and statistically significant data, we would need the subjects to be very specific, for example, involving highly qualified athletes of weightlifting sports or people with an exceptional 
proportion of skeletal muscles [57]. Such subjects, for instance, can also include some ethnicities, considering their residence [33].

\section{Problems with Sample Collection}

Because the occurrence of the MSTNK153R rs 1805086 allele in populations is $7 \%$ on an average, it creates problems in identifying people with the rare genotype [32]. Two of the factors that significantly affect the association of myostatin genotypes with muscle mass and skeletal muscle strength are sex and age. Experiments to identify the effect of myostatin on muscle mass and strength showed different results depending on these two factors $[65,66]$.

Contradictory data were also obtained in cases where the subjects were representative of different sports [57]. The impact of myostatin on skeletal muscle strength depends on the sport. In the type of sport requiring the ability to maintain a given physical load for a long time, no statistically significant data were found on the association of MSTN polymorphisms with muscle mass and strength [62].

Some studies have reported that female estrogens affect the change in the expression of myostatin caused by power-oriented physical exercises [65]. In addition, differences in ethnicity, sample size, body weight, and level of physical activity may be potential reasons for the different results in studies related to myostatin [67]. The authors pointed out that nutritional factors should be considered when assessing the level of myostatin. Sex is also an important factor in the reduction of muscle strength and age-related decrease in muscle mass. Men usually begin to lose muscle mass after 40 years of age, when the level of testosterone in serum drops. Women can gradually lose $10-15 \%$ of their muscle mass from the age over 25 until the onset of menopause, after which it increases at a rate of $2 \%$ annually. Therefore, the amount of muscle mass is also affected by sex and diet.

In addition, studies often consider a specific human muscle as an object, such as the biceps or quadriceps, and this is also a limiting factor for the full assessment of the relationship between myostatin and the muscle mass and strength of the entire body as a whole.

The absence of a control group in some studies does not allow us to solve the problem of statistical validity of the obtained data [56]. To obtain the most reliable data, larger sample sizes are required.

Finally, after testing for strength exercises, researchers considered only some indicators of muscle fatigue; therefore, they were limited to confirming the connection mechanism between specific strength indicators, myostatin genotype, and muscle strength. It should be noted that most scientific publications are primarily based on previous research [67-69].

There are studies in which the authors concluded that the K153R MSTN allele does not affect muscle phenotypes in women, wherein their sample of subjects was 33 people aged between 90-97-years-old. Considering that this allele is very rare, the results of such studies seem very doubtful [20]. 
Thus, in this manuscript, the systematic review of publications related to the influence of the $K 153 R$ allele of MSTN helped conclude that the data obtained can be regarded as contradictory. With such a discrepancy, the question arises whether the allelic variants $K$ and $R$ of the MSTN rs1805086 gene are genetic factors that can affect human strength abilities and skeletal muscle hypertrophy.

Meta-analysis overcomes the limitation of a small sample size by combining the results of a number of individual studies to obtain a single best estimate.

\section{Meta-analysis}

\section{Goal of Research}

The purpose of this study was to summarize the relationship between K153R polymorphism and athletes' strength indicators by conducting a systematic review and meta-analysis, which can potentially reveal more statistically reliable data compared to individual studies.

\section{Materials and Methods}

\section{Search for Publications}

The search for scientific publications was carried out using PubMed, Web of Science, eLIBRARY.ru, SNPedia, Wiley Online Library, and Europe PMC resource databases. For this, we used the following keywords: myostatin, MSTN, GDF-8, K153R, and rs1805086. We compiled a list of publications on myostatin, which included 71 scientific articles published prior to April 2021 from the above databases. For the analysis and systematization of publications, we used the EndNote Viever X9.2 bibliographic managers of Clarivate Analytics and the Zotero application. In addition to analyzing the content of the publications, we also studied their references. After selecting all potentially relevant articles, all the information on the K153R MSTN rs1805086 allele was carefully studied in the control and experimental groups.

\section{Inclusion and Exclusion Criteria}

Out of 71 scientific articles in PubMed, Web of Science, eLibrary.ru, SNPedia, Ensembl, Wiley Online Library, and Europe PMC databases, we selected publications that were directly related to the study of the K153R genotype (rs1805086). All the studies we used were marked with the following statement: "The study was approved by the ethics committee."

To be included in this review, the studies had to meet the following criteria:

1. Be published from 1997 to April 2021,

2. Sample size should not be less than 10 people, and a control group in the study is mandatory,

3. Full text of the study should be available,

4. Participants must be adults who are not elderly, 
5. Subjects had to be healthy at the time of the study,

6. No studies should be conducted on animals.

Of the 71 scientific articles, 61 were excluded after the first stage of working with databases. The criteria for rejecting the work included discrepancy between the title and subject of the study, experiments on animals, and experiments with a small sample. The main criterion for dropping out publications in the first stage was that the studies were not related to the K153R MSTN polymorphism.

After analyzing ten full-text publications, six were excluded after the second stage. These articles were devoted either to the expression of myostatin or they had inadequate methodological quality of experiments. As a result, four publications $[13,56,61,70]$ were included in the meta-analysis. A flowchart showing the algorithm for selecting publications for the meta-analysis is shown in Figure 4.

\section{Data Extraction}

To include the publication in the meta-analysis, we analyzed the full text of each study for the general content and its compliance with the aforementioned acceptance criteria. From each eligible article the following data were obtained: authors, publication year, study organization, study population (number of subjects, ethnicity, gender), polymorphism number and name, muscle phenotype.

The phenotypic data included in this analysis were skeletal muscle mass and muscle strength.

\section{Statistical Analysis}

We used the computer program Review Manager 5.4.1 (RevMan) to perform the meta-analysis proposed by the Cochrane Community in 2014. The meta-analysis used data on the number of genotypes in the control and experimental groups. To check for "publication error" (a systematic error associated with the predominant publication of positive results), we analyzed the asymmetry of the funnel graph [71]. The relationship between the K153R polymorphism and phenotypic data and the strength abilities of the subjects were evaluated using the odds ratio (OR) criterion and $95 \%$ confidence interval $(\mathrm{Cl})$ by comparing the control and experimental groups. The heterogeneity of the obtained data was estimated using heterogeneity index $\mathrm{I}^{2}$ [72]. In the test for the overall effect, which was set according to the Z-criterion, the two-sided value of $P$ was considered significant.

We also analyzed the statistical significance of each study included in the meta-analysis to compare the significance of this study with the generalized indicators. The degree of statistical significance of each study was assessed by $\chi^{2}$, in which $P$ values $<0.05$, were considered statistically significant. Statistical analysis according to the $\chi^{2}$-criterion was carried out using SPSS 23.0.

Based on the fact that in some publications the results of genotyping of subjects were expressed in nucleotides, whereas in others as amino acids, we used the following designations: the amino acid "Lys" was designated by the letter " $\mathrm{K}$ ", and "Arg" by the letter "R". Thus, the mutant allele was designated by the letter "R". 


\section{Results}

As mentioned earlier, the frequency of mutant homozygotes (RR) is below $1 \%$ among the general population, which limits the possibility of studying large groups of people with variant $R$. On the other hand, according to Ensembl base, the frequency of the mutant allele R, is approximately $3-4 \%$ on an average in among the general population across the globe. Among the athletes of power and weightlifting sports, the frequency of the minor allele R and the homozygote RR was significantly higher, reaching to $10 \%[70]$.

In this study, we found that athletes with the R MSTN allele had significantly greater muscle strength and mass due to the power-oriented physical training compared with that of the carriers of the K MSTNallele. This indicates that the presence of the $\mathrm{R}$ allele in MSTN rs 1805086 can be considered a genetic marker associated with increased skeletal muscle strength and muscle mass $(O R=2.02, P=0.05)$.

\section{Discussion}

\section{Case-Control Study}

In the control group of African American athletes, the frequency of the RR rs1805086 genotype was higher in $2-3 \%$ of cases than in the control groups in Russian and Caucasus natives. The $K R$ heterozygote was also more common in the African-American control group than in the Russian control group (Table 1). In addition, the rs $1805086 K R / R R$ genotypes were also significantly more common in the African-American athletes (35\% and $14 \%$ vs. $13.0 \%$ and $7.1 \%$, respectively) (Table 2 ).

Table 1

K153R MSTNallele frequency distribution in the athlete and control groups

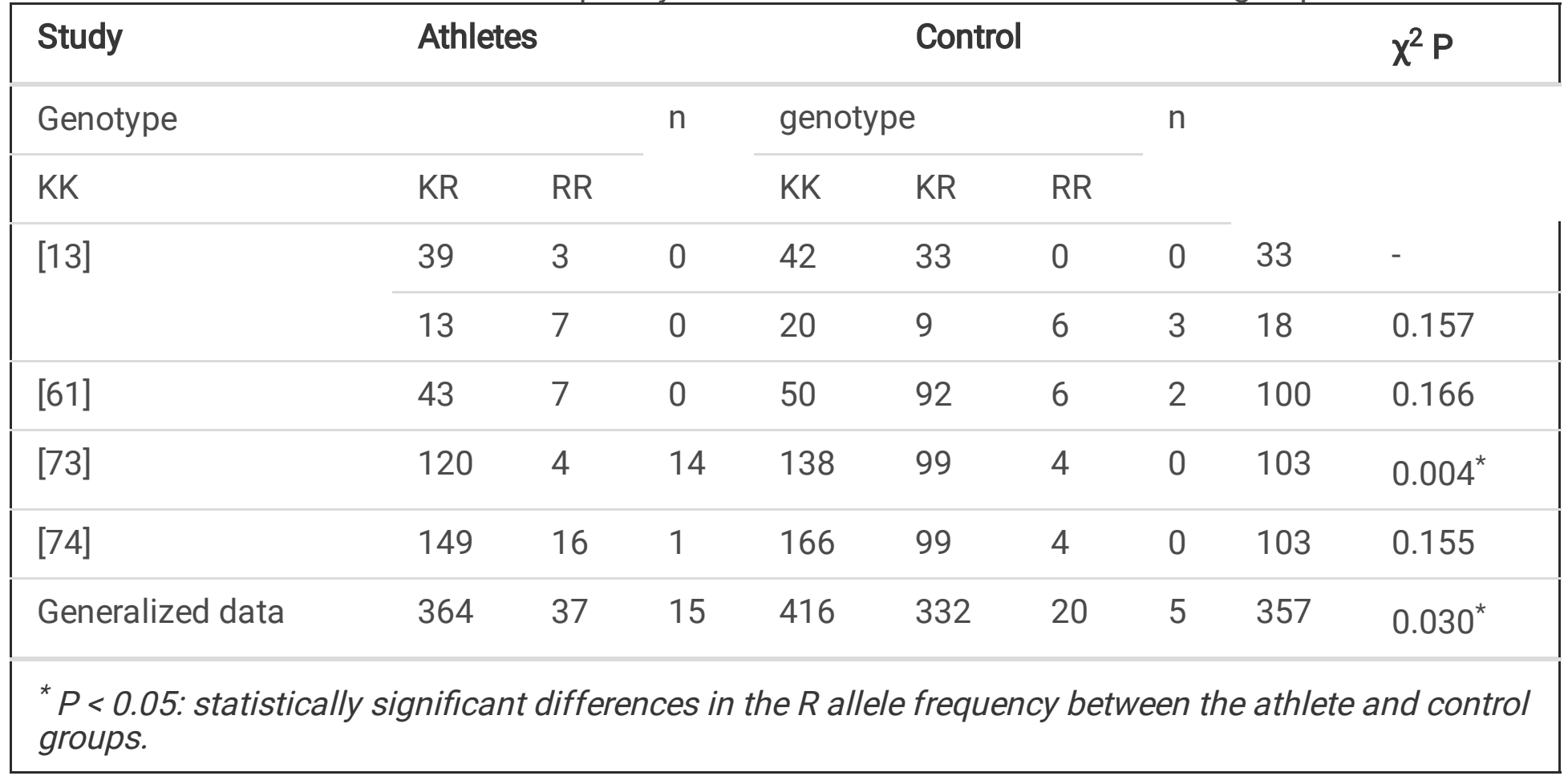


Table 2. K153R MSTN genotypes distribution in the athlete and control groups

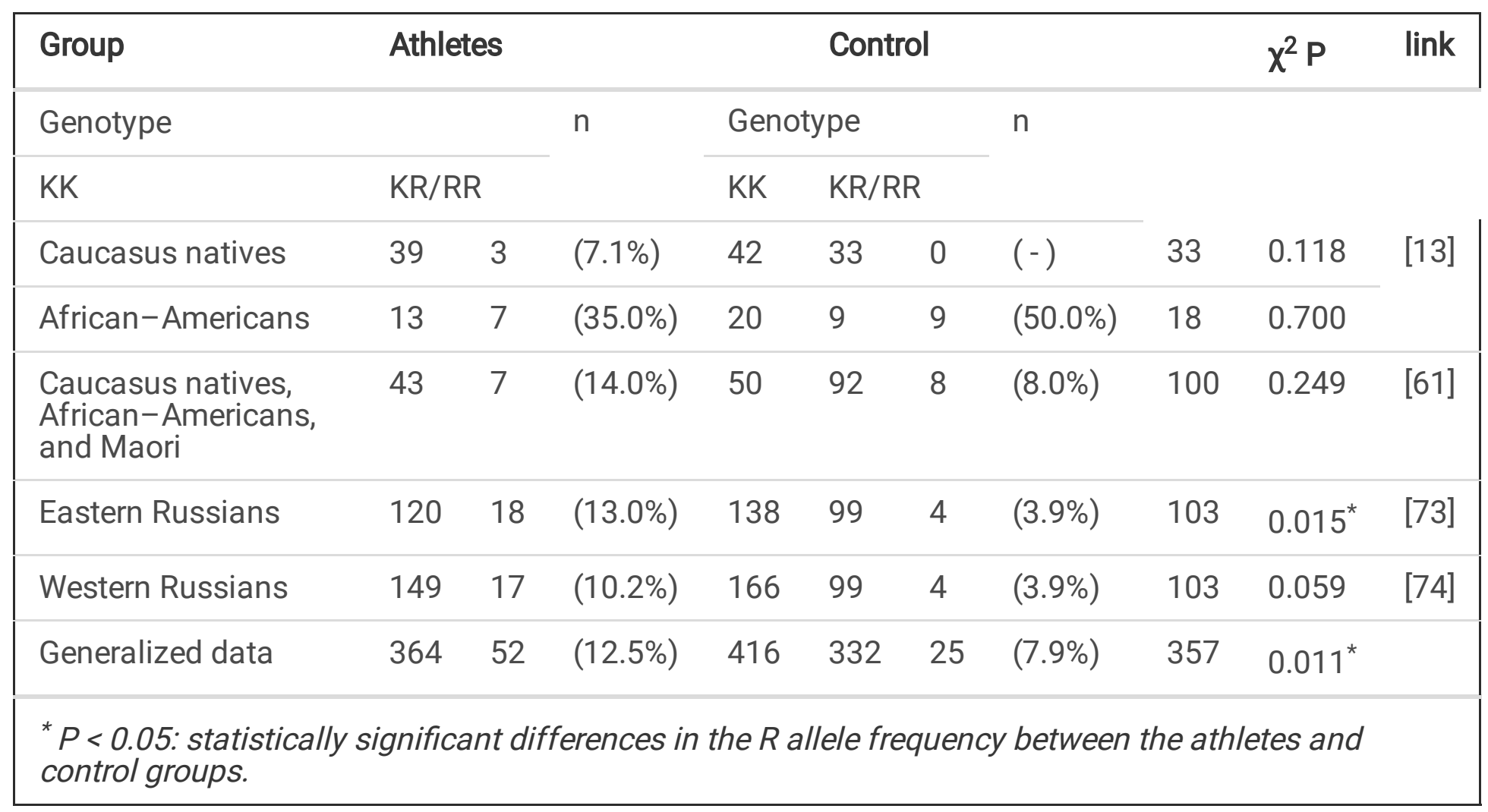

Checking the statistical significance of the obtained data by conducting a Chi-square test $\left(\chi^{2}\right)$ for the analysis of each sample separately did not show any statistically significant results, with the exception of the Russian subjects of 2017 [70]; however, the generalization of the data yielded statistically significant results $(P=0.030)$ for the analysis of genotypes $K K, K R$, and $R R$, and $P=0.0011$ for the genotypes $K R$ and KK/RR.

When searching for publications in several databases, four suitable studies were found in which athletes of weightlifting sports were compared with subjects in a control group. The feature of comparison was the polymorphism K153R MSTN. After combining the data from the selected studies, the group of athletes with the rare $R$ allele comprised of 52 subjects, and the control group comprised 25 subjects $(12.5 \%$ vs. $7.9 \%$, respectively). The generalized data showed statistically significant differences ( $P=$ 0.011 ) according to the $\chi^{2}$-criterion. The rare occurrence of this allele did not allow us to obtain statistically significant differences separately, with the exception of a sample of Eastern Russians [73, 74]. Combining the samples into a single general population made it possible to increase the level of statistical significance of the analyzed data.

The data reported by Usac G. (2020) were not included in the meta-analysis, in which the author studied 79 Turkish athletes (arm wrestlers) aged 24 years in comparison with a control group consisting of 34 people. Associative studies were conducted on two polymorphisms of MSTN, A55T, and K153R. The authors failed to find statistically significant relationships between the studied polymorphisms and 
anthropometric indicators. Perhaps the reason for such data was the absence of genotypes with the R allele among the group of athletes [56].

In another study, the authors found that the currently published data on the MSTN K153R polymorphism and the human muscle phenotypes show contradictory results [65]. A number of studies have reported a significant effect of MSTN variants, and the reaction of muscle mass in response to strength training regardless of sex, which confirms the hypertrophic response to strength training in adults of both sexes. The $153 R$ allele is associated with a greater muscle hypertrophic response to exercise [75].

Santiago et al. (2011) studied the relationship between the K153R MSTN polymorphism and "explosive" leg strength in untrained men, and they were able to prove that the K153R MSTN polymorphism is associated with the ability to generate "peak" power during muscle contractions, evaluated using the vertical jump test. The authors indicated that the polymorphisms Lys $(K)$ and $153 \operatorname{Arg}(R)$ located in exon 2 (replacement rs1805086, $2379 A>G$ ) affect the phenotype of skeletal muscles. The replacement of the amino acid Lys $(K)$ with $153 \operatorname{Arg}(R)$ was found in the active mature peptide of the myostatin protein, and this replacement can affect proteolytic processing due to its propeptide or the ability to bind to ActRIIB, which in turn, induces myoblast proliferation and muscle mass differentiation.

A study conducted in China on 94 healthy untrained men of the age group 8-22 years, convincingly demonstrated that the increase in the thickness of biceps $(\bar{\square}=0.300 \pm 0.131 \mathrm{~cm})$ and quadriceps $(\bar{\square}=$ $0.421 \pm 0.281 \mathrm{~cm})(P<0.01$ for both muscle groups) was significantly higher among individuals with the $K R$ genotype than among those with the KK genotypes of the K153R MSTN polymorphism. Thus, the obtained results proved that this polymorphism leads to a larger skeletal muscle size in the absence of training and is also associated with a more noticeable increase in muscle mass after strength training in subjects with the $\mathrm{R}$ allele [52].

The frequency of rs $1805086 K R / R R$ genotypes was significantly higher in the group of athletes than that of those in the control group (Table 2). African-American athletes were an exception. This may be due to the fact that, according to the Ensembl resource, the frequency of $K 153 R$ polymorphism worldwide is significantly higher among African-Americans (average of 22\%) than in other populations (Figure 1).

In general, five case-control studies were used for the meta-analysis, in which 416 athletes and 357 subjects from the control group participated. The frequencies of the $K R / R R$ genotypes compared to that of the $K K$ genotype were significantly higher in the group of athletes $(12.5 \%)$ compared to the control group $(95 \% \mathrm{Cl}, \mathrm{P}=0.011)$. The results of the meta-analysis were as follows: the random effects model: $\mathrm{OR}=2.02, \mathrm{P}=0.05, \mathrm{Z}=1.94$ (Table 3 ) and fixed effects model: $\mathrm{OR}=2.15,95 \% \mathrm{Cl}, \mathrm{P}=0.05$; (Table 4). The coefficient of heterochrony between the studies was $I^{2}=33 \%(P=0.20)$. These results show that the mutation of the $\mathrm{R}$ allele (i.e., the $K R / R R$ genotypes) has a statistically significant relationship with the phenotype of athletes with respect to the development of skeletal muscle strength abilities and muscle mass. 
This is the first study to demonstrate the results of a meta-analysis of the K153R MSTN allele with the phenotype and functions of skeletal muscles in athletes. In particular, we found that the frequency of genotypes that contribute to an increase in muscle volume and skeletal muscle strength in athletes ( $K R$ and $R R$ genotypes) was significantly higher in the experimental group than in the control group. It was also confirmed that the $K 153 R$ mutation is more common in the African-American group than that in other groups. In addition, a meta-analysis of five groups (two African-Americans, one Caucasus native, and two Russian), including a total of 773 test athletes and 357 general people in the control group, showed a significantly higher prevalence of $K R / R R$ genotypes in the athletes than that in the control group.

The $K 153 R$ polymorphism is significant in the development of muscle mass and strength. Previously, a number of studies have also shown that the rare $R$ allele increases the inhibition of myostatin synthesis, thereby leading to an increase in skeletal muscle mass and muscle strength [37]. The hypothesis that the effectiveness of strength training is significantly higher in athletes with the $R$ MSTN rs 1805086 allele was confirmed by a meta-analysis (table 3 , table 4 ).

The $\mathrm{R}$ allele is favorable for sports in which muscle strength and mass are important, such as bodybuilding, powerlifting, weightlifting, arm wrestling, kettlebell lifting, shot put, and bobsleigh. It can be assumed that the strong effect of this allele on the ability to become a successful athlete in weightlifting and speed-power sports is based on the inhibition of myostatin synthesis, as reported in some previous studies. In their respective studies, researchers, including F. M. Ivey, S. M. Roth, R. E. Ferrell have established a trend of the influence of the K153R MSTN genotype on the hypertrophic response of skeletal muscles in response to strength training in women with the heterozygotic genotype. Experiments have shown an increase in leg muscle mass in subjects with the $K R$ genotype in response to strength training, this was $68 \%$ higher than that in women with the $K K$ genotype $(P=0.056)[75]$. These data also indicate a significant role of the rare allele $R$ in MSTN in the hypertrophic response of the muscles of the subjects. The authors note that the K153R MSTN polymorphism has not been sufficiently studied and needs further research, particularly in women with high body weight. In addition, of interest is the reaction of the muscular system in response power-oriented physical load, taking into account the MSTN genotypes.

It should also be noted that in almost all the publications found, the authors indicated that the data obtained in the conducted studies may be limited by the levels of statistical significance of the statistical processing methods used. This is due to the low frequency of the R MSTN allele. Therefore, further studies with larger sample sizes are needed to solve this problem. In addition, as in most studies related to the K153R MSTN polymorphism in athletes, we believe that it is necessary to conduct experiments aimed at identifying associations between other MSTN polymorphisms and the expression of the myostatin protein in order to obtain additional information about the mechanisms by which myostatin polymorphisms affect the effectiveness of the training process for increasing muscle mass and developing athletes' strength abilities. 


\section{Conclusion}

Meta-analysis of data on the K153R MSTNallele (rs1805086) convincingly demonstrated that the $K R$ and $R R$ genotypes are statistically significantly associated with the strength abilities of athletes and their muscle mass when performing power-oriented training. Combining efforts in searching for subjects with the rare $R$ MSTN allele will allow us to obtain more significant information about the magnitude of the effect of this polymorphism during strength training. Other polymorphisms of myostatin and its molecular mechanisms should also be studied, which will allow us to understand the factors that contribute to an increase in muscle strength and mass in more depth.

A deeper understanding of the mechanisms that control the maintenance of strength abilities of skeletal muscles will help to increase the effectiveness of sports selection, add to the list of molecular markers of sports inclinations, and develop more effective methods for the development of athletes' strength abilities.

It is well-known that inhibition of myostatin expression leads to an increase in muscle mass and improves muscle regeneration. Perhaps, future studies will need to be performed to explore the relationship between myostatin and stem cells, which will allow us to obtain new data on the molecular mechanisms by which myostatin affects the manifestation of the abilities of weightlifting athletes. A better understanding of the molecular mechanisms of myostatin inhibition, including power-oriented physical load, is likely to be a promising area for improving the professional skills of weightlifting athletes.

\section{Declarations}

Competing interests: The authors declare no competing interests.

\section{References}

1. Beunen G., Thomis M. Gene powered? Where to go from heritability $(\mathrm{H}-2)$ in muscle strength and power? // Exercise and Sport Sciences Reviews. - 2004. - T. 32, № 4. - C. 148-154.

2. Mangine G. T., Hoffman J. R., Gonzalez A. M., Townsend J. R., Wells A. J., Jajtner A. R., Beyer K. S., Boone C. H., Miramonti A. A., Wang R., LaMonica M. B., Fukuda D. H., Ratamess N. A., Stout J. R. The effect of training volume and intensity on improvements in muscular strength and size in resistancetrained men // Physiological Reports. - 2015. - T. 3, № 8. - C. 17.

3. Rodriguez J., Vernus B., Chelh I., Cassar-Malek I., Gabillard J. C., Sassi A. H., Seiliez I., Picard B., Bonnieu A. Myostatin and the skeletal muscle atrophy and hypertrophy signaling pathways // Cellular and Molecular Life Sciences. - 2014. - T. 71, № 22. - C. 4361-4371.

4. Yamada A. K., Verlengia R., Bueno C. R. Myostatin: genetic variants, therapy and gene doping // Brazilian Journal of Pharmaceutical Sciences. - 2012. - T. 48, № 3. - C. 369-377. 
5. Dalbo V. J., Roberts M. D., Sunderland K. L., Poole C. N., Stout J. R., Beck T. W., Bemben M., Kerksick C. M. Acute Loading and Aging Effects on Myostatin Pathway Biomarkers in Human Skeletal Muscle After Three Sequential Bouts of Resistance Exercise // Journals of Gerontology Series a-Biological Sciences and Medical Sciences. - 2011. - T. 66, № 8. - C. 855-865.

6. Allen D. L., Hittel D. S., McPherron A. C. Expression and Function of Myostatin in Obesity, Diabetes, and Exercise Adaptation // Medicine and Science in Sports and Exercise. - 2011. - T. 43, № 10. - C. 1828-1835.

7. Zheng L.-F., Chen P.-J., Xiao W.-H. Signaling pathways controlling skeletal muscle mass // Book Signaling pathways controlling skeletal muscle mass / Editor, 2019. - C. 671-679.

8. Roth S. M., Martel G. F., Ferrell R. E., Metter E. J., Hurley B. F., Rogers M. A. Myostatin gene expression is reduced in humans with heavy resistance strength training: A brief communication // Experimental Biology and Medicine. - 2003. - T. 228, № 6. - C. 706-709.

9. Shishkin S. S. Miostatin i nekotorye drugie biohimicheskie faktory, reguliruyushchie rost myshechnyh tkanej u cheloveka i ryada vysshih pozvonochnyh // Book Miostatin i nekotorye drugie biohimicheskie faktory, reguliruyushchie rost myshechnyh tkanej u cheloveka i ryada vysshih pozvonochnyh / Editor, 2004. - C. 209-262.

10. McPherron A. C., Lawler A. M., Lee S. J. Regulation of skeletal muscle mass in mice by a new TGFbeta superfamily member // Nature. - 1997. - T. 387, № 6628. - C. 83-90.

11. Kollias H. D., McDermott J. C. Transforming growth factor-beta and myostatin signaling in skeletal muscle // Journal of Applied Physiology. - 2008. - T. 104, № 3. - C. 579-587.

12. McFarlane C., Hui G. Z., Amanda W. Z. W., Lau H. Y., Lokireddy S., Ge X. J., Mouly V., Butler-Browne G., Gluckman P. D., Sharma M., Kambadur R. Human myostatin negatively regulates human myoblast growth and differentiation // American Journal of Physiology-Cell Physiology. - 2011. - T. 301, № 1. - C. C195-C203.

13. Ferrell R. E., Conte V., Lawrence E. C., Roth S. M., Hagberg J. M., Hurley B. F. Frequent sequence variation in the human myostatin (GDF8) gene as a marker for analysis of muscle-related phenotypes // Genomics. - 1999. - T. 62, № 2. - C. 203-207.

14. Sergeeva K. V., Miroshnikov A. B., Smolensky A. V. Effect of Growth Hormone Administration on the Mass And Strength of Muscles in Healthy Young Adults: a Systematic Review and Meta-Analysis // Human Physiology. - 2019. - T. 4. - C. 462-460.

15. Pan H., Ping X. C., Zhu H. J., Gong F. Y., Dong C. X., Li N. S., Wang L. J., Yang H. B. Association of myostatin gene polymorphisms with obesity in Chinese north Han human subjects // Gene. - 2012. - T. 494, № 2. - C. 237-241.

16. Thomis M. A., Huygens W., Peeters M., Vlietinck R., Beunen G. P. Linkage analysis of myostatinpathway genes in human adiposity: The Leuven Genes for Muscular Strength Project // Medicine and Science in Sports and Exercise. - 2004. - T. 36, № 5. - C. S99-S99.

17. Gonzalez-Cadavid N. F., Bhasin S. Role of myostatin in metabolism // Current Opinion in Clinical Nutrition and Metabolic Care. - 2004. - T. 7, № 4. - C. 451-457. 
18. Han D. S., Huang C. H., Chen S. Y., Yang W. S. Serum reference value of two potential doping candidates-myostatin and insulin-like growth factor-l in the healthy young male // Journal of the International Society of Sports Nutrition. - 2017. - T. 14.

19. Lakshman K. M., Bhasin S., Corcoran C., Collins-Racie L. A., Tchistiakova L., Forlow S. B., Ledger K. S., Burczynski M. E., Dorner A. J., LaVallie E. R. Measurement of myostatin concentrations in human serum: Circulating concentrations in young and older men and effects of testosterone administration // Molecular and Cellular Endocrinology. - 2009. - T. 302, № 1. - C. 26-32.

20. Gonzalez-Freire M., Rodriguez-Romo G., Santiago C., Bustamante-Ara N., Yvert T., Gomez-Gallego F., Rexach J. A. S., Ruiz J. R., Lucia A. The K153R variant in the myostatin gene and sarcopenia at the end of the human lifespan // Age. - 2010. - T. 32, № 3. - C. 405-409.

21. Sharma M., McFarlane C., Kambadur R., Kukreti H., Bonala S., Srinivasan S. Myostatin: Expanding horizons // lubmb Life. - 2015. - T. 67, № 8. - C. 589-600.

22. Feder D., Rugollini M., Santomauro A., Oliveira L. P., Lioi V. P., dos Santos R., Ferreira L. G., Nunes M. T., Carvalho M. H., Delgado P. O., Carvalho A. A. S., Fonseca F. L. A. Erythropoietin reduces the expression of myostatin in mdx dystrophic mice // Brazilian Journal of Medical and Biological Research. - 2014. - T. 47, № 11. - C. 966-971.

23. Gentile M. A., Nantermet P. V., Vogel R. L., Phillips R., Holder D., Hodor P., Cheng C., Dai H. Y., Freedman L. P., Ray W. J. Androgen-mediated improvement of body composition and muscle function involves a novel early transcriptional program including IGF1, mechano growth factor, and induction of betacatenin // Journal of Molecular Endocrinology. - 2010. - T. 44, № 1. - C. 55-73.

24. Kim J. S., Cross J. M., Bamman M. M. Impact of resistance loading on myostatin expression and cell cycle regulation in young and older men and women // American Journal of PhysiologyEndocrinology and Metabolism. - 2005. - T. 288, № 6. - C. E1110-E1119.

25. Lach-Trifilieff E., Minetti G. C., Sheppard K., Ibebunjo C., Feige J. N., Hartmann S., Brachat S., Rivet H., Koelbing C., Morvan F., Hatakeyama S., Glass D. J. An Antibody Blocking Activin Type II Receptors Induces Strong Skeletal Muscle Hypertrophy and Protects from Atrophy // Molecular and Cellular Biology. - 2014. - T. 34, № 4. - C. 606-618.

26. Jespersen J. G., Nedergaard A., Andersen L. L., Schjerling P., Andersen J. L. Myostatin expression during human muscle hypertrophy and subsequent atrophy: increased myostatin with detraining // Scandinavian Journal of Medicine \& Science in Sports. - 2011. - T. 21, № 2. - C. 215-223.

27. Lee S. J., McPherron A. C. Regulation of myostatin activity and muscle growth // Proceedings of the National Academy of Sciences of the United States of America. - 2001. - T. 98, № 16. - C. 93069311.

28. Walker R. G., Poggioli T., Katsimpardi L., Buchanan S. M., Oh J., Wattrus S., Heidecker B., Fong Y. W., Rubin L. L., Ganz P., Thompson T. B., Wagers A. J., Lee R. T. Biochemistry and Biology of GDF11 and Myostatin Similarities, Differences, and Questions for Future Investigation // Circulation Research. 2016. - T. 118, № 7. - C. 1125-1141. 
29. Hill J. J., Qiu Y. C., Hewick R. M., Wolfman N. M. Regulation of myostatin in vivo by growth and differentiation factor-associated serum protein-1: A novel protein with protease inhibitor and follistatin domains // Molecular Endocrinology. - 2003. - T. 17, № 6. - C. 1144-1154.

30. Huang Z. Q., Chen X. L., Chen D. W. Myostatin: A novel insight into its role in metabolism, signal pathways, and expression regulation // Cellular Signalling. - 2011. - T. 23, № 9. - C. 1441-1446.

31. Drummond M. J., Glynn E. L., Fry C. S., Dhanani S., Volpi E., Rasmussen B. B. Essential Amino Acids Increase MicroRNA-499,-208b, and-23a and Downregulate Myostatin and Myocyte Enhancer Factor 2C mRNA Expression in Human Skeletal Muscle // Journal of Nutrition. - 2009. - T. 139, № 12. - C. 2279-2284.

32. Ben-Zaken S., Meckel Y., Nemet D., Rabinovich M., Kassem E., Eliakim A. Frequency of the MSTN Lys(K)-153Arg $(R)$ polymorphism among track \& field athletes and swimmers // Growth Hormone \& Igf Research. - 2015. - T. 25, № 4. - C. 196-200.

33. Fuku N., Alis R., Yvert T., Zempo H., Naito H., Abe Y., Arai Y., Murakami H., Miyachi M., Pareja-Galeano H., Emanuele E., Hirose N., Lucia A. Muscle-Related Polymorphisms (MSTN rs1805086 and ACTN3 rs1815739) Are Not Associated with Exceptional Longevity in Japanese Centenarians // Plos One. 2016. - T. 11, № 11.

34. Joulia-Ekaza D., Cabello G. The myostatin gene: physiology and pharmacological relevance // Current Opinion in Pharmacology. - 2007. - T. 7, № 3. - C. 310-315.

35. Kostyunina D. S., Ivanova A. D., Smirnova O. V. Myostatin: 20 years later // Book Myostatin: 20 years later / EditorHuman physiology, 2018. - C. 99-114.

36. Baczek J., Silkiewicz M., Wojszel Z. B. Myostatin as a Biomarker of Muscle Wasting and other Pathologies-State of the Art and Knowledge Gaps // Nutrients. - 2020. - T. 12, № 8. - C. 22.

37. Szlama G., Trexler M., Buday L., Patthy L. K153R polymorphism in myostatin gene increases the rate of promyostatin activation by furin // Febs Letters. - 2015. - T. 589, № 3. - C. 295-301.

38. Walsh F. S., Celeste A. J. Myostatin: a modulator of skeletal-muscle stem cells // Biochemical Society Transactions. - 2005. - T. 33. - C. 1513-1517.

39. Zhang Z. L., He J. W., Qin Y. J., Hu Y. Q., Li M., Zhang H., Hu W. W., Liu Y. J., Gu J. M. Association between myostatin gene polymorphisms and peak BMD variation in Chinese nuclear families // Osteoporosis International. - 2008. - T. 19, № 1. - C. 39-47.

40. Elkasrawy M. N., Hamrick M. W. Myostatin (GDF-8) as a key factor linking muscle mass and bone structure // Journal of Musculoskeletal \& Neuronal Interactions. - 2010. - T. 10, № 1. - C. 56-63.

41. Zhu J., Li Y., Shen W., Qiao C., Ambrosio F., Lavasani M., Nozaki M., Branca M. F., Huard J. Relationships between transforming growth factor-beta 1, myostatin, and decorin - Implications for skeletal muscle fibrosis // Journal of Biological Chemistry. - 2007. - T. 282, № 35. - C. 2585225863.

42. Guo W., Flanagan J., Jasuja R., Kirkland J., Jiang L., Bhasin S. The effects of myostatin on adipogenic differentiation of human bone marrow-derived mesenchymal stem cells are mediated 
through cross-communication between Smad3 and Wnt/beta-catenin signaling pathways // Journal of Biological Chemistry. - 2008. - T. 283, № 14. - C. 9136-9145.

43. Artaza J. N., Bhasin S., Magee T. R., Reisz-Porszasz S., Shen R. Q., Groome N. P., Fareez M. M., Gonzalez-Cadavid N. F. Myostatin inhibits myogenesis and promotes adipogenesis in C3H 10T(1/2) mesenchymal multipotent cells // Endocrinology. - 2005. - T. 146, № 8. - C. 3547-3557.

44. Hamrick M. W., Arounleut P., Kellum E., Cain M., Immel D., Liang L. F. Recombinant Myostatin (GDF-8) Propeptide Enhances the Repair and Regeneration of Both Muscle and Bone in a Model of Deep Penetrant Musculoskeletal Injury // Journal of Trauma-Injury Infection and Critical Care. - 2010. - T. 69, № 3. - C. 579-583.

45. Thomis M. A. I., Huygens W., Heuninckx S., Chagnon M., Maes H. H. M., Claessens A. L., Vlietinck R., Bouchard C., Beunen G. P. Exploration of myostatin polymorphisms and the angiotensin-converting enzyme insertion/deletion genotype in responses of human muscle to strength training // European Journal of Applied Physiology. - 2004. - T. 92, № 3. - C. 267-274.

46. Santiago C., Ruiz J. R., Rodriguez-Romo G., Fiuza-Luces C., Yvert T., Gonzalez-Freire M., GomezGallego F., Moran M., Lucia A. The K153R Polymorphism in the Myostatin Gene and Muscle Power Phenotypes in Young, Non-Athletic Men // Plos One. - 2011. - T. 6, № 1. - C. 5.

47. Garatachea N., Pinos T., Camara Y., Rodriguez-Romo G., Emanuele E., Ricevuti G., Venturini L., SantosLozano A., Santiago-Dorrego C., Fiuza-Luces C., Yvert T., Andreu A. L., Lucia A. Association of the K153R polymorphism in the myostatin gene and extreme longevity // Age. - 2013. - T. 35, № 6. - C. 2445-2454.

48. Schuelke M., Wagner K. R., Stolz L. E., Hubner C., Riebel T., Komen W., Braun T., Tobin J. F., Lee S. J. Brief report - Myostatin mutation associated with gross muscle hypertrophy in a child // New England Journal of Medicine. - 2004. - T. 350, № 26. - C. 2682-2688.

49. Catipovic B. Myostatin mutation associated with gross muscle hypertrophy in a child // New England Journal of Medicine. - 2004. - T. 351, № 10. - C. 1030-1030.

50. Williams M. S. Myostatin mutation associated with gross muscle hypertrophy in a child // New England Journal of Medicine. - 2004. - T. 351, № 10. - C. 1030-1030.

51. Corsi A. M., Ferrucci L., Gozzini A., Tanini A., Brandi M. L. Myostatin polymorphisms and age-related sarcopenia in the Italian population // Journal of the American Geriatrics Society. - 2002. - T. 50, № 8. - C. 1463-1463.

52. Li X., Wang S. J., Tan S. C., Chew P. L., Liu L. H., Wang L., Wen L., Ma L. H. The A55T and K153R polymorphisms of MSTN gene are associated with the strength training-induced muscle hypertrophy among Han Chinese men // Journal of Sports Sciences. - 2014. - T. 32, № 9. - C. 883-891.

53. Kostek M. A., Angelopoulos T. J., Clarkson P. M., Gordon P. M., Moyna N. M., Visich P. S., Zoeller R. F., Price T. B., Seip R. L., Thompson P. D., Devaney J. M., Gordish-Dressman H., Hoffman E. P., Pescatello L. S. Myostatin and Follistatin Polymorphisms Interact with Muscle Phenotypes and Ethnicity // Medicine and Science in Sports and Exercise. - 2009. - T. 41, № 5. - C. 1063-1071. 
54. Bhatt S. P., Nigam P., Misra A., Guleria R., Luthra K., Jain S. K., Pasha M. A. Q. Association of the Myostatin Gene with Obesity, Abdominal Obesity and Low Lean Body Mass and in Non-Diabetic Asian Indians in North India // Plos One. - 2012. - T. 7, № 8.

55. Kim J., Park K., Lee J. Myostatin A55T Genotype is Associated with Strength Recovery Following Exercise-Induced Muscle Damage // International Journal of Environmental Research and Public Health. - 2020. - T. 17, № 13. - C. 8.

56. Usac G., Eroglu O., Zileli R. The Evaluation of RS1805086 and RS1805065 Polymorphisms in Mstn Gene and Anthropometric Properties of National and Amateur Arm Wrestlers // International Journal of Morphology. - 2020. - T. 38, № 4. - C. 1148-1154.

57. Grealy R., Herruer J., Smith C. L. E., Hiller D., Haseler L. J., Griffiths L. R. Evaluation of a 7-Gene Genetic Profile for Athletic Endurance Phenotype in Ironman Championship Triathletes // Plos One. 2015. - T. 10, № 12. - C. 20.

58. Fernandez-Santander A., Valveny N., Harich N., Kandil M., Luna F., Martin M. A., Rubio J. C., Lucia A., Gaibar M. Polymorphisms influencing muscle phenotypes in North-African and Spanish populations // Annals of Human Biology. - 2012. - T. 39, № 2. - C. 166-169.

59. Juffer P., Furrer R., Gonzalez-Freire M., Santiago C., Verde Z., Serratosa L., Morate F. J., Rubio J. C., Martin M. A., Ruiz J. R., Arenas J., Gomez-Gallego F., Lucia A. Genotype Distributions in Top-level Soccer Players: A Role for ACE? // International Journal of Sports Medicine. - 2009. - T. 30, № 5. C. 387-392.

60. Aksenov M. O., Andryushchenko L. B. Myostatin gene role in strength building process // Book Myostatin gene role in strength building process / Editor, 2018. - C. 71-73.

61. Filonzi L., Franchini N., Vaghi M., Chiesa S., Nonnis Marzano F. The potential role of myostatin and neurotransmission genes in elite sport performances // Journal of Biosciences. - 2015. - T. 40, № 3 . - C. 531-537.

62. Ben-Zaken S., Meckel Y., Nemet D., Eliakim A. The combined frequency of IGF and myostatin polymorphism among track \& field athletes and swimmers // Growth Hormone \& Igf Research. 2017. - T. 32. - C. 29-32.

63. Khanal P., He L. X., Herbert A. J., Stebbings G. K., Onambele-Pearson G. L., Degens H., Morse C. I., Thomis M., Williams A. G. The Association of Multiple Gene Variants with Ageing Skeletal Muscle Phenotypes in Elderly Women // Genes. - 2020. - T. 11, № 12. - C. 18.

64. Peng L. N., Lee W. J., Liu L. K., Lin M. H., Chen L. K. Healthy community-living older men differ from women in associations between myostatin levels and skeletal muscle mass // Journal of Cachexia Sarcopenia and Muscle. - 2018. - T. 9, № 4. - C. 635-642.

65. Seibert M. J., Xue Q. L., Fried L. P., Walston J. D. Polymorphic variation in the human myostatin (GDF8) gene and association with strength measures in the Women's Health and Aging Study II cohort // Journal of the American Geriatrics Society. - 2001. - T. 49, № 8. - C. 1093-1096.

66. Tosun Tasar P., Sahin S., Karaman E., Oz A., Ulusoy M. G., Duman S., Berdeli A., Akcicek F. Myostatin Gene Polymorphism in an Elderly Sarcopenic Turkish Population // Genetic Testing and Molecular 
Biomarkers. - 2015. - T. 19, № 8. - C. 457-460.

67. Elliott B., Renshaw D., Getting S., Mackenzie R. The central role of myostatin in skeletal muscle and whole body homeostasis // Acta Physiologica. - 2012. - T. 205, № 3. - C. 324-340.

68. McNally E. M. Powerful genes - Myostatin regulation of human muscle mass // New England Journal of Medicine. - 2004. - T. 350, № 26. - C. 2642-2644.

69. Matsakas A., Diel P. The growth factor myostatin, a key regulator in skeletal muscle growth and homeostasis // International Journal of Sports Medicine. - 2005. - T. 26, № 2. - C. 83-89.

70. Aksenov M. O. Theoretical and methodological foundations of building the training process in weightlifting sports, taking into account genetic characteristics // Book Theoretical and methodological foundations of building the training process in weightlifting sports, taking into account genetic characteristics / Editor. - Banzarov Buryat State University. Ulan-Ude, 2017. - C. 407.

71. Egger M., Smith G. D., Schneider M., Minder C. Bias in meta-analysis detected by a simple, graphical test // Bmj-British Medical Journal. - 1997. - T. 315, № 7109. - C. 629-634.

72. Higgins J. P. T., Thompson S. G. Quantifying heterogeneity in a meta-analysis // Statistics in Medicine. - 2002. - T. 21, № 11. - C. 1539-1558.

73. Aksenov M. O. Teoretiko-metodicheskie osnovy postroeniya trenirovochnogo processa v tyazheloatleticheskih vidah sporta s uchetom geneticheskih osobennostej. Dissertaciya doktorata pedagogicheskih nauk: Ulan-Ude, 2017. 407 pp.

74. Aksenov M. O. Fundamentals of the training process in weightlifting sports taking into account genetic features. Ulan-Ude: Publishing House of the Buryat State University Department, 2018. 300 pp.

75. Ivey F. M., Roth S. M., Ferrell R. E., Tracy B. L., Lemmer J. T., Hurlbut D. E., Martel G. F., Siegel E. L., Fozard J. L., Metter E. J., Fleg J. L., Hurley B. F. Effects of age, gender, and myostatin genotype on the hypertrophic response to heavy resistance strength training // Journals of Gerontology Series aBiological Sciences and Medical Sciences. - 2000. - T. 55, № 11. - C. M641-M648.

\section{Tables 3-4}

Tables 3-4 are available in the Supplementary Files section.

\section{Figures}


150

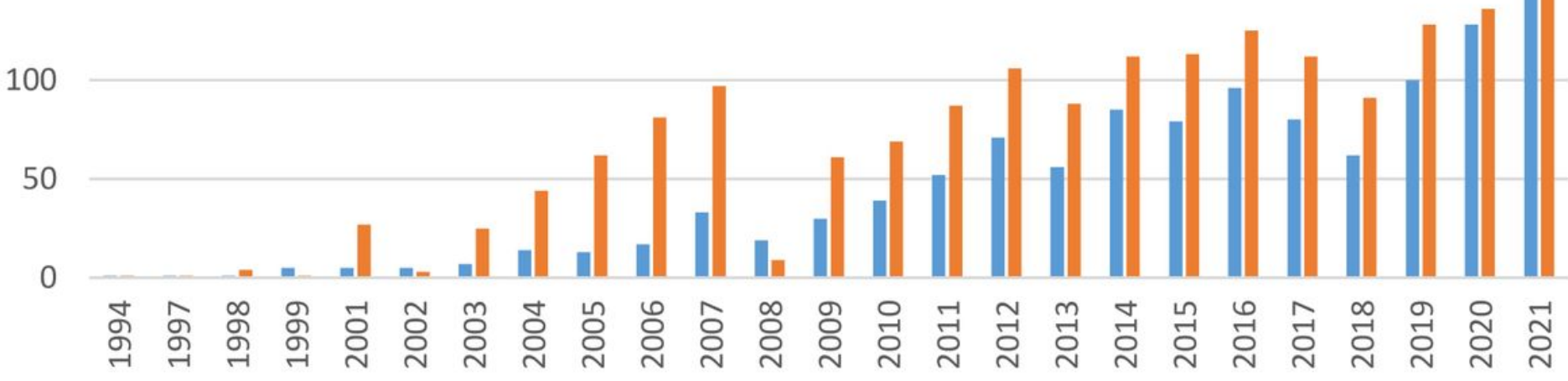

$\square$ WoS $\square \mathrm{NCBI}$

\section{Figure 1}

Dynamics of publications on myostatin (data as on December, 2021)

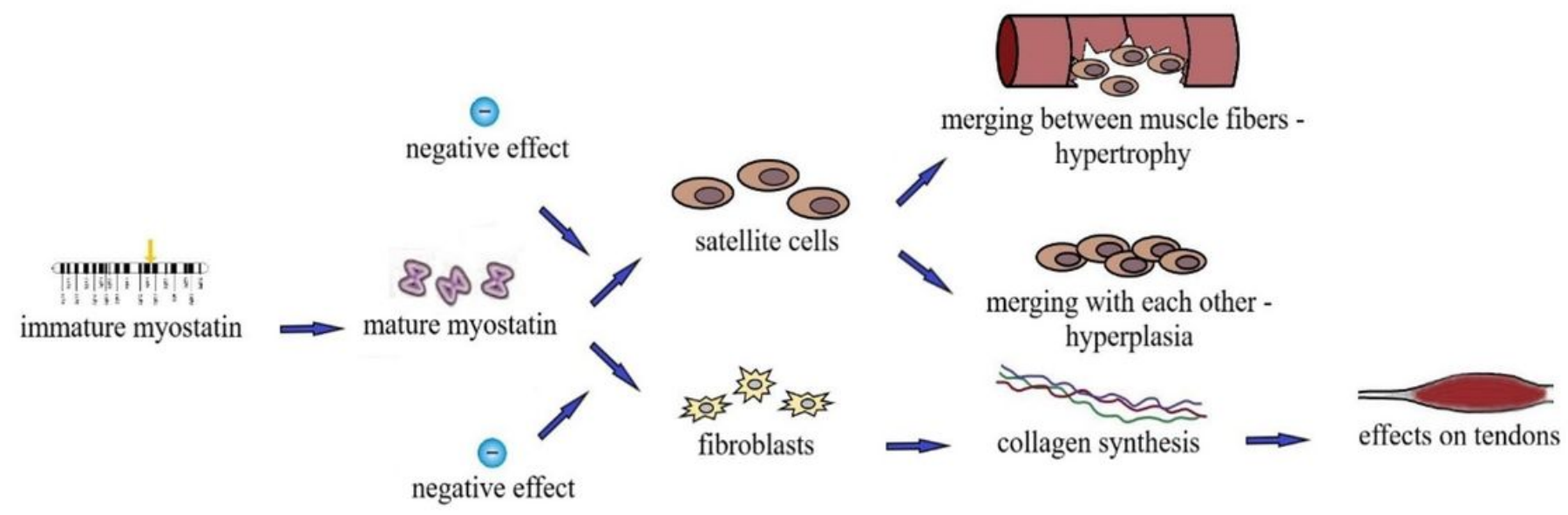

Figure 2

Molecular mechanisms of athletes' strength abilities 


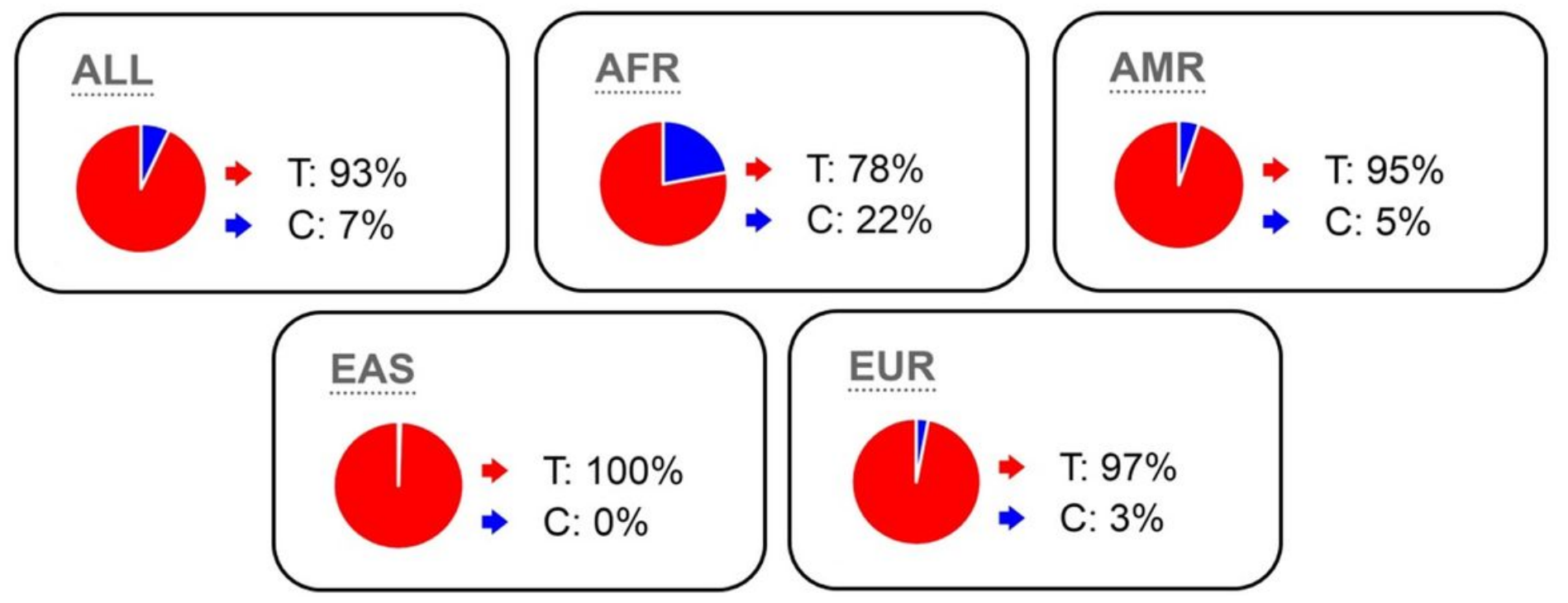

All-General picture; AFR- African; AMR- American; EAS- Asian; EUR- Caucasian

Figure 3

Allele frequencies of MSTNK153R polymorphism according to the Ensembl database 


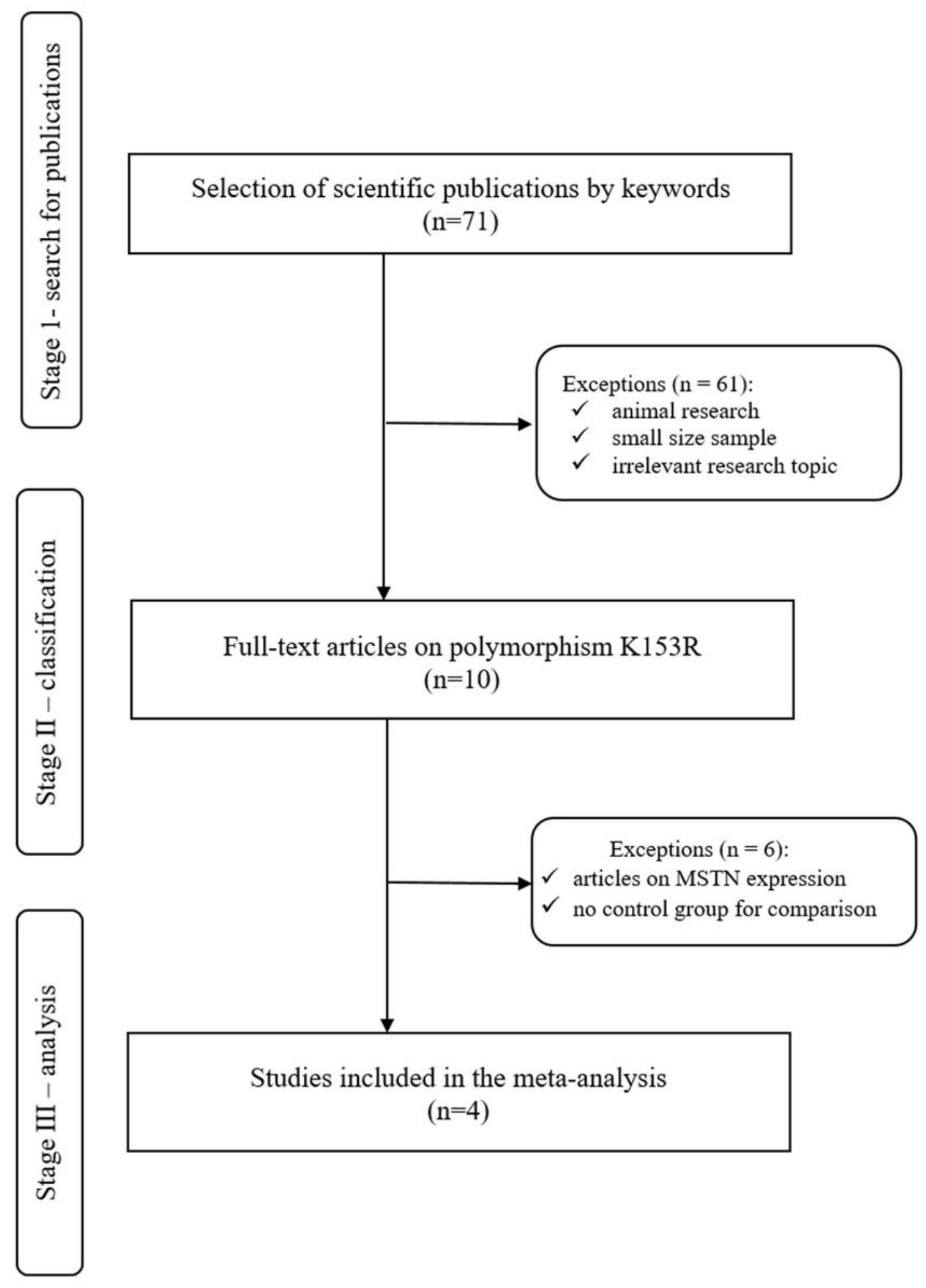

Figure 4

A flowchart representing the algorithm for selecting publications included in the meta-analysis

\section{Supplementary Files}

This is a list of supplementary files associated with this preprint. Click to download. 
- Table3.jpg

- Table4.jpg 